\title{
Unidirectional Braking Energy Recovery System for Elevators
}

\author{
Kaspars Kroics \\ Institute of Industrial Electronics and \\ Electrical Engineering \\ Riga Technical University \\ Riga, Latvia \\ kaspars.kroics@rtu.lv
}

\begin{abstract}
The paper discusses design of energy storage based energy recovery system for elevators. The main element of such system is unidirectional DC-DC converter to control energy flow to supercapacitor or li-ion battery based energy storage. The paper gives explanation of selection of the converter topology and some design considerations. The test results of experimental prototype on a developed test bench are presented in the paper.
\end{abstract}

Keywords-DC-DC converter, supercapacitors, energy efficiency, electrical drive, isolated converter.

\section{INTRODUCTION}

Energy efficiency of an elevator can be improved by storing the regenerated braking energy produced during descending of heavy loads and ascending of light loads. The proposed solution is to integrate DC-DC converter together with supercapacitors into one module and retrofit existing electrical drive system of the elevator to increase energy efficiency. The structure of the energy recovery system is shown in Fig. 1. Such system makes the elevator system energy efficient.

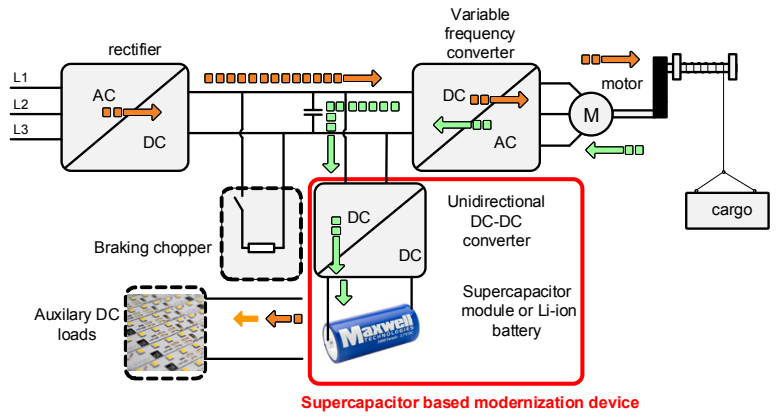

Fig. 1. The application of supercapacitor based retrofit device in elevator or lifting device system.

To utilize low voltage energy storage unidirectional DC-DC converter is required. The stored energy later can be used to supply auxiliary DC loads such as LED lightening and elevator control system. Induction motor or permanent magnet motor together with frequency converter is used more frequently to drive elevator mechanisms. If the motor is pushed rotating faster than the synchronous speed, then it will move to regenerative braking mode and generate electricity. The braking energy still is wasted as heat in braking resistors in more than 90 percent of all installed elevators [1]. By useful utilizing of this energy could be stored from 20 to $40 \%$ of electrical energy. In other cases regenerative variable frequency drives are used that supplies braking energy back into AC grid. If there are no electrical loads into shared facilities electricity should be supplied back to the utility network. The price for this electricity is low, therefore, payback time of regenerative drive system can be much longer as in case with a local storage with a DC-DC converter - one example is shown in Fig. 2.

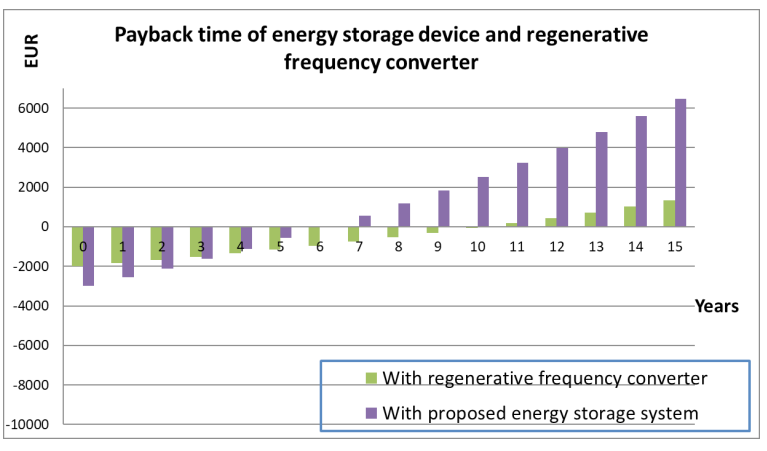

Fig. 2. Payback period of regeneretive AC drive and energy storage system.

In the example shown in Fig. 2 consumption of the elevator is equal to $7000 \mathrm{kWh}$, energy savings $40 \%$ and electricity price in Latvia. The approximate price of the regenerative variable frequency converter is equal to 2000 EUR but price of proposed energy storage system - 3000 EUR. Taken into consideration that price of electricity purchased from the grid operator is at least 3 times higher than price for electricity delivered back to grid operator the payback time of energy storage system can be much shorter although the initial investments is higher.

The central part of the proposed solution is unidirectional power electronic converter which should detect braking mode and provide optimal power flow to the storage. It is important to reduce the current ripple and improve the efficiency of the converter. One of possibility is to use multilevel interleaved DC-DC converter topology. In such way it is possible to improve efficiency as low voltage transistors have better parameters and reduce current ripple as the currents are shifted in phase and therefore current ripples are much lower.

Print ISSN 1691-5402

Online ISSN 2256-070X

http://dx.doi.org/10.17770/etr2019vol3.4173

(C) 2019 Kaspars Kroics.

Published by Rezekne Academy of Technologies.

This is an open access article under the Creative Commons Attribution 4.0 International License. 
Interleaving control schemes of the DC-DC converters more and more often are used in the converter applications, especially, in the converters that require high power capability and high performance. Benefits of such control methods include reduction of size, losses and cost of the input and output filter, reduction of current stress of the DC bus capacitor, improved dynamic performance and increase in the power capacity of the converters. Interleaved DC-DC converters are used in various applications: as voltage regulation modules [2], [3] renewable applications [4], [5], [6], [7], [8], traction applications [9]-[14] and in the other application areas. In this case benefit from utilizing interleaved topology is possibility to reduce the size and losses in output inductors.

\section{DC-DC Converter DESCRIPTION}

As a converter topology for particular application input-series output-parallel (ISOP) configuration is selected that consists of two modular DC-DC converters connected in series at the input and in parallel at the output (Fig. 3), enabling the use of high switching frequency MOSFETs with low voltage ratings, which leads to a higher power density and a high conversion efficiency. As output current ripple frequency is twice of the switching frequency, size and costs of the output filter can be reduced. The voltage of both legs of the converter due to unequal values of passive components and delays in control signals may differ. If this issue is solved without changing the control system, the control of the converter can be realized as for conventional DC-DC converter just signals should be shifted in phase by 180 degrees.

If in the ISOP the converter balancing of the voltages of both legs is not provided, the difference in currents through transistors causes misbalance of the capacitors voltage and this will lead to failure. The difference of currents of both legs can be caused by unequal inductances of the inductors, transformers, unlike parameters of semiconductors or different duty cycle, especially, in the transient process. Misbalance in the voltage causes larger current in the leg with higher voltage so slow process of stabilization will take place, but mostly it is not enough to keep voltage of the capacitor in the desired level. Therefore, it is necessary to find a solution to prevent the situation when voltage of the capacitor reaches dangerous value and damages semiconductors or passive elements. of the capacitor reaches dangerous value and damages semiconductors or passive elements.

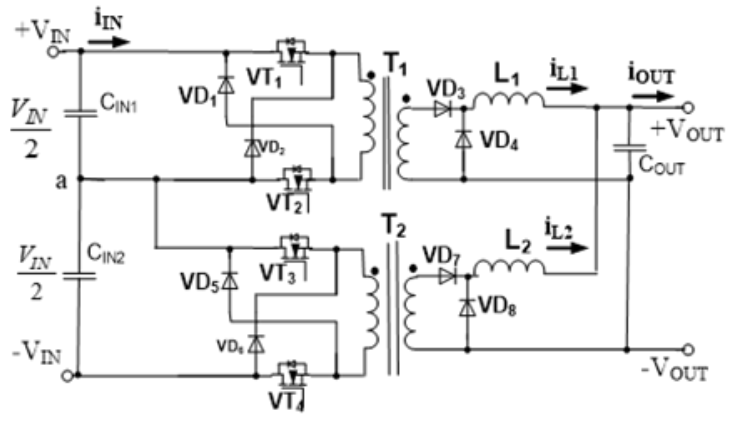

Fig. 3. Schematics of ISOP forward DC-DC converter.
Fig. 4 shows structure of the proposed transformer which consists of round ferrite core and three windings. Number of turns of the secondary winding and balancing winding are equal to 27 . For the balancing winding wire with cross sectional area equal to $0,2 \mathrm{~mm} 2$ is used. For the secondary winding litz wire with cross sectional area equal to $7 \mathrm{~mm}^{2}$ is used. The balancing resistor in series with balancing winding must be selected according to desired rapidity of voltage balancing process. Should be considered that resistor with low resistance leads to higher current therefore cross sectional area of the balancing winding must be increased if it is required faster balancing process. In the particular case balancing resistor has value around $800 \mathrm{Ohm}$. The power losses in this circuit is low therefore compact balancing resistor can be used with power of less than watt, additional balancing windings can be created by using wire with small cross-sectional area.

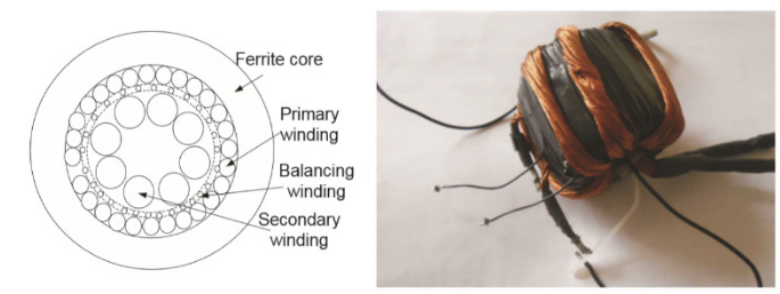

Fig. 4. The transformer for ISOP converter configuration with integrated balancing winding.

Fig. 5 shows the oscillograms with voltage balancing process. The voltage equalization circuit is not provided to hold equal voltages in all conditions. The main task of the balancing winding is to ensure that voltage does not reach dangerous value. In particular case there is voltage shifting margin of safety equal to 70 volts as maximum allowed voltage of the input capacitor is equal to 350 $\mathrm{V}$. And other task is equate voltages when misbalance current is over.

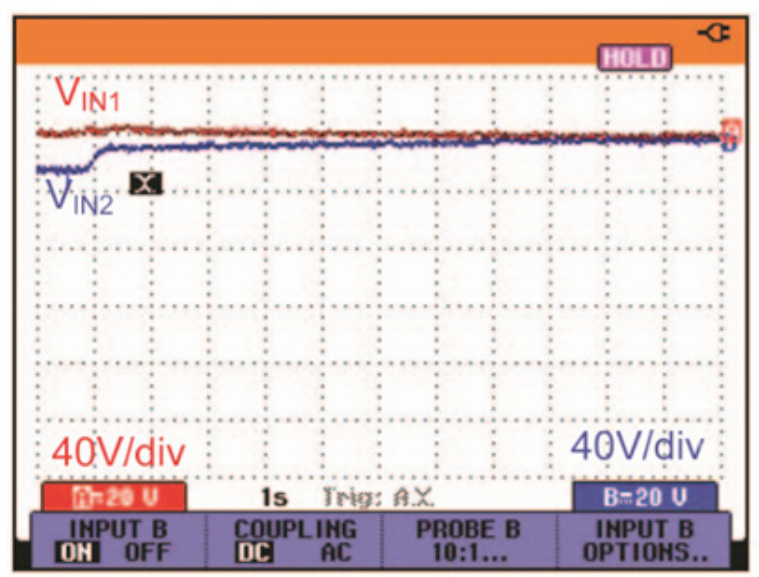

Fig. 5. The process of voltage balancing.

In the oscillograms shown in the Fig. 5 during first moment the converter works with full load but in mode with small duty cycle therefore voltage balancing circuit cannot fully compensate misbalance current but the voltage stays in the safety margin. After reducing of the load balancing circuit equalize both voltages. The oscilogram is measured in the short circuit and no load conditions in which the voltage equalizing process is the worst as duty cycle in these modes is small. But even in the following 
conditions balancing circuit works satisfactorily. More detailed description of the balancing circuit design and working principle can be found in [15]-[17]

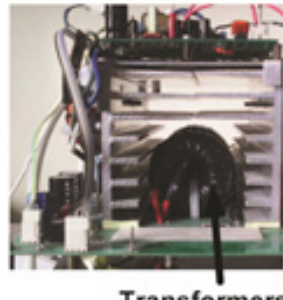

Transformer

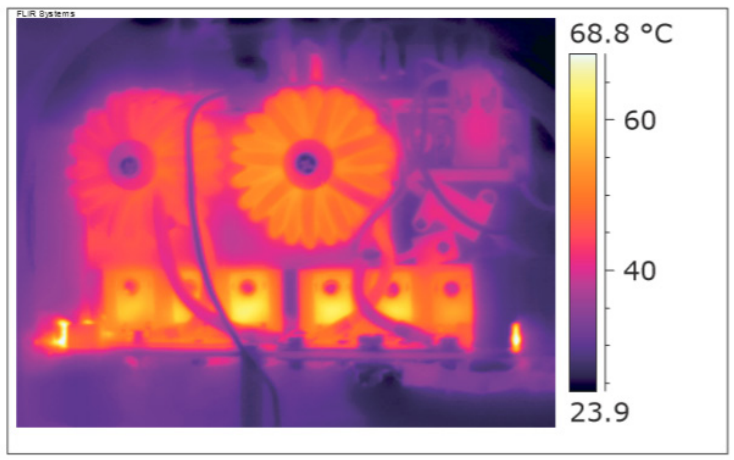

Fig. 7. The thermal image of the converter working at full load.

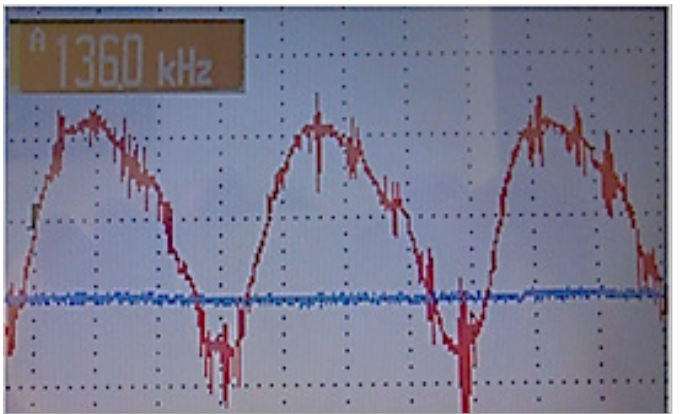

Fig. 8. Output current ripple (blue line) and current ripple in the inductor (red line).

The ISOP converter is designed for input voltage $600 \mathrm{~V}$ DC and output voltage from 0-30 volts, output current $100 \mathrm{~A}$. The control of the converter is realized by using DSP microcontroller. Fig. 6 shows hardware of the converter, for transformer design it is used N87 material two ring ferrite cores to increase effective cross sectional area of the core. For inductor it is used metal powder cores. Output diodes are connected 3 in parallel to minimize power losses. Input capacitors have high value as converter also was tested far from the 3 phase rectified AC power DC bus, this value can be significantly reduced. The transformer based drivers were designed to drive MOSFET transistors. To cool down the semiconductors and magnetic elements the converter is equipped with radiator and electric fan. As can be seen in Fig. 7 the temperature of the converter elements does not exceed critical values under nominal load. In Fig. 8 are shown current ripples in the output inductor of one phase and summary output current, Due to interleaved topology these ripples can be eliminated fully by using relatively small output capacitor therefore size and price of the converter can be reduced.
III. Design of Test Bench to Emulate Energetic Processes of ELEVATOR

The energy recovery system that includes unidirectional DC-DC converter and series connection of supercapacitors is connected to the DC link of the traction drive simulator. The DC-DC converter operates in a stepdown mode and provides supercapacitor or Li-ion battery charging, after that the stored energy is slowly discharged by powering auxiliary DC loads.

Fig. 9 shows hardware of the developed test bench - in this case ABB VFDs and braking resistors are used and CEO electric motors are used. The test bench control system is developed to test on test bench bi-directional DC-DC converter for energy recovery application in elevator system.

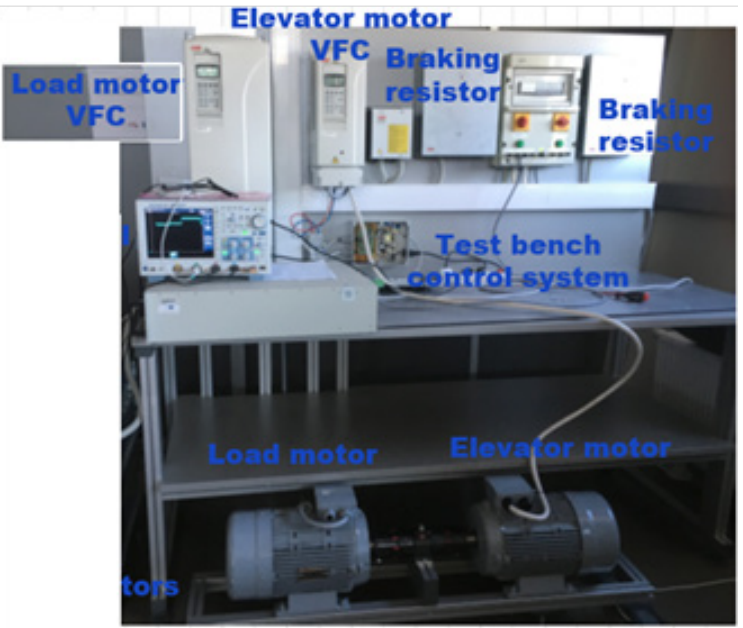

Fig. 9. Hardware implementation of the test bench.

In case of elevator the out of balance torque can be referred to the motor as follows:

$M=\frac{m_{o . b .} \cdot g \cdot D}{2 \cdot i \cdot \eta}$,

where $\mathrm{m}_{\text {o.b. }}$ - out of balance mass (considering counterweight);

$\mathrm{g}$ - is the acceleration due to gravity;

$\mathrm{D}$ - is the diameter of the sheave in $\mathrm{m}$;

$i$ is the reduction ratio of the gearbox;

$\eta$ is the efficiency of the installation.

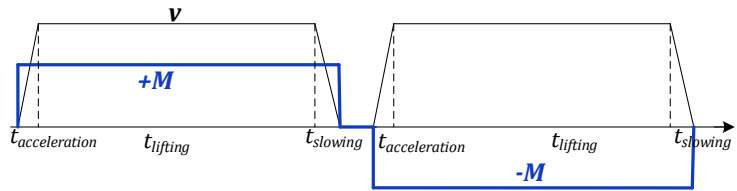

Fig. 10. The analog reference control signals send to the VFDs in case of elevator emulation.

As the acceleration equal to $0.8-1.0 \mathrm{~m} / \mathrm{s}^{2}$ is acceptable and is set in settings of VFD of the elevator motor there is no need to calculate inertia of the system. Fig. 10 shows control signals to VFDs in case of elevator. The elevator motor VFD is controlled by providing speed reference signal to VFD analog input (black curve in Fig. 10). The elevator motor accelerates to the constant speed and then keeps constant speed till it slows down with a desired slow down time. The load emulation motor VFD is controlled by providing analogue torque reference signal 
(blue curve in Fig. 10). During the braking mode the control system generates negative torque reference signal to load emulation VFD. Other alternative can be reversing rotational speed of the elevator VFD and provide positive moment - it is more close to real elevator but from the energy flow point of view there is no difference therefore in particular application rotational speed is selected only in one direction.

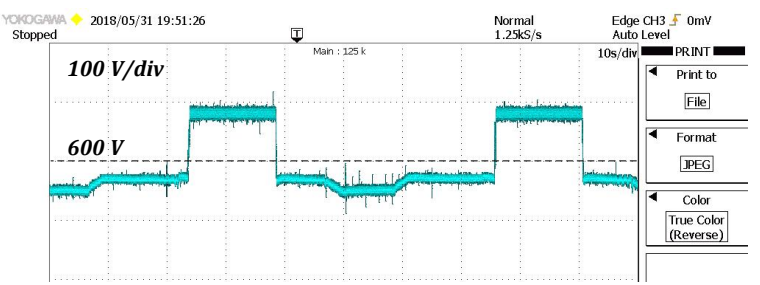

Fig. 11. Voltage of DC bus during two cycles implemented on test bench.

Fig. 11. shows DC bus voltage of elevator motor VFD, it is possible clearly indicate the braking time of period when the voltage goes up till the braking chopper operating voltage. During the lifting mode the voltage drops down. More detailed description of the development of test bench can be found in [18].

\section{EXPERImental Analysis of ENERgy Recovery SYSTEM}

The particular converter is designed to control input voltage at $600 \mathrm{~V} \mathrm{DC}$ level. If the elevator system is in the braking mode, the DC bus voltage increases as can be seen in Fig. 11 and converter control loop is designed in a such a way to regulate DC bus voltage equal to 600 V DC. As can be seen in Fig. 12 such voltage regulation works well and it is possible to charge battery with a braking power that in other case will be lost in the braking resistor. The output voltage of the converter is from 0-30 volts, nominal output current $100 \mathrm{~A}$. The control of the converter is realized by using DSP microcontroller.

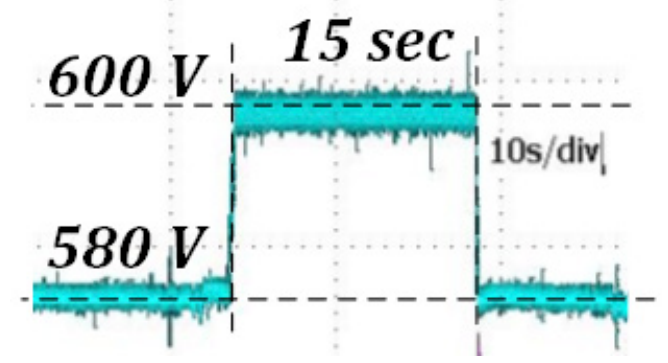

Fig. 12. DC bus voltage during charge mode of the battery.

The efficiency of the converter is approximately 90 percent but it is possible efficiency improvement by using semiconductors with better parameters and by implementing soft-switching circuits.

\section{Conclusions}

In the paper proposed method to improve energy efficiency of the elevators by using unidirectional DCDC converter and energy storage. Developed DC-DC converter have efficiency around 90 percent but the benefit is that such converter is inexpensive and therefore payback time of energy storage system will be shorter.

To test energy recovery system test bench was developed that allows experimental testing of energy storage system in laboratory. The experimental results show proper operation of the energy storage system, further goal is the efficiency improvement of the converter without significant increasing price of electronics components used to develop such converter. Also integration of such system in solar DC power system can be as one of the further goals.

\section{REFERENCES}

[1] "Energy-efficient elevators and escalators in Europe: An analysis of energy efficiency potentials and policy measures - ScienceDirect." [Online]. Available: https://www.sciencedirect.com/science/article/pii/S0378778811006530. [Accessed: 28-Feb-2019].

[2] P.-L. Wong, P. Xu, P. Yang, and F. C. Lee, "Performance improvements of interleaving VRMs with coupling inductors," IEEE Transactions on Power Electronics, vol. 16, no. 4, pp. 499-507, Jul. 2001.

[3] Y. Panov and M. M. Jovanovic, "Design considerations for 12-V/1.5-V, 50-A voltage regulator modules," IEEE Transactions on Power Electronics, vol. 16, no. 6, pp. 776-783, Nov. 2001.

[4] D. Arnaudov and S. Vuchev, "Multiphase converters for charging of energy storage elements," in 2016 XXV International Scientific Conference Electronics (ET), 2016, pp. 1-3.

[5] J. Zakis, D. Vinnikov, and L. Bisenieks, "Some design considerations for coupled inductors for integrated buck-boost converters," in 2011 International Conference on Power Engineering, Energy and Electrical Drives, 2011, pp. 1-6.

[6] J. Shen, K. Rigbers, and R. W. D. Doncker, "A Novel Phase-Interleaving Algorithm for Multiterminal Systems," IEEE Transactions on Power Electronics, vol. 25, no. 3, pp. 741-750, Mar. 2010.

[7] K. Kroics, J. Zakis, and U. Sirmelis, "Multiphase interleaved DC-DC converter with directly and inversely coupled inductors," in 2016 57th International Scientific Conference on Power and Electrical Engineering of Riga Technical University (RTUCON), 2016, pp. 1-6

[8] K. Kroics, A. Sokolovs, U. Sirmelis, and L. Grigans, "Interleaved series input parallel output forward converter with simplified voltage balancing control," in PCIM Europe 2016; International Exhibition and Conference for Power Electronics, Intelligent Motion, Renewable Energy and Energy Management, 2016, pp. 1-8.

[9] M. A. Shrud, A. Bonsbaine, A. S. Ashur, R. Thorn, and T. Benmusa, "Modeling and simulation of automotive interleaved buck converter," in 2009 44th International Universities Power Engineering Conference (UPEC), 2009, pp. 1-5.

[10] J. Czogalla, J. Li, and C. R. Sullivan, "Automotive application of multi-phase coupled-inductor DC-DC converter," in 38th IAS Annual Meeting on Conference Record of the Industry Applications Conference, 2003., 2003, vol. 3, pp. 1524-1529 vol.3.

[11] M. Hirakawa et al., "High power DC/DC converter using extreme close-coupled inductors aimed for electric vehicles," in The 2010 International Power Electronics Conference - ECCE ASIA -, 2010, pp. 2941-2948.

[12]D. Arnaudov, N. Hinov, S. Vuchev, and I. Nedyalkov, "Modeling of Multiphase Converter for Charging of Energy Storage Elements," in PCIM Europe 2017; International Exhibition and Conference for Power Electronics, Intelligent Motion, Renewable Energy and Energy Management, 2017, pp. 1-7.

[13] V. Brazis, K. Kroics, and L. Grigans, "Scientific Laboratory Platform for Testing the Electric Vehicle Equipped with DC Drive," Latvian Journal of Physics and Technical Sciences, vol. 51, no. 5, Jan. 2014.

[14]K. Kroics and J. Zakis, "Electronic Ballast for Gas Discharge Lamp Based on Input-Series Output-Series Resonant Converter," in PCIM Europe 2017; International Exhibition and Conference for Power Electronics, Intelligent Motion, Renewable Energy and Energy Management, 2017, pp. 1-7.

[15]K. Kroics, U. Sirmelis, and V. Brazis, "Voltage balance control of two-level DC-DC converter," in Engineering for rural development, 2015, pp. 402-407. 
[16]K. Kroics, J. Zakis, A. Suzdalenko, and G. Gaigals, “A simplified approach to input voltage balancing for series connected isolated DC-DC converters," in 2016 18th European Conference on Power Electronics and Applications (EPE'16 ECCE Europe), 2016, pp. 1-10.

[17] U. Sirmelis, L. Grigans, K. Kroics, and J. Zakis, "Isolated DC/dc converter based voltage measuring system for series connected supercapacitor cells," in 2015 9th International Conference on Compatibility and Power Electronics (CPE), 2015, pp. 443-446.
[18]K. Kroics, "Development of Induction Motor Based Test Bench for Supercapacitor Braking Energy Recovery System Testing," in 2018 IEEE 59th International Scientific Conference on Power and Electrical Engineering of Riga Technical University (RTUCON), 2018, pp. 1-5.

[19]K. Kroics, J. Zakis, A. Suzdalenko, and G. Gaigals, “A simplified approach to input voltage balancing for series connected isolated DC-DC converters," in 2016 18th European Conference on Power Electronics and Applications (EPE'16 ECCE Europe), 2016, pp. 1-10 